\title{
A IMPORTÂNCIA DO ACOLHIMENTO ESPIRITUAL EM TEMPOS DE COVID-19
}

\section{THE IMPORTANCE OF SPIRITUAL ACCOMMODATION IN COVID-19 TIMES}

\section{$10.31072 /$ rcf.v12i2.951}

\section{Júlia Graziele Santos Nunes}

Graduanda em Enfermagem pela Faculdade de Educação e Meio Ambiente - FAEMA/RO.

E-mail: julia.g.s.n@hotmail.com.

Monise Nunes Bezerra iD

Graduanda em Enfermagem pela Faculdade de Educação e Meio Ambiente - FAEMA/RO.

E-mail: monisenunesbezerra@gmail.com

Elis Milena F. do C. Ramos

Mestranda em Saúde e Educação pela Universidade de Ribeirão Preto UNAERP, professora na Faculdade de Educação e Meio Ambiente FAEMA/RO.

E-mail: elis.milena81@gmail.com.

Submetido: 19 abr. 2021.

Aprovado: 24 ago. 2021.

Publicado: 30 ago. 2021.

E-mail para correspondência: monisenunesbezerra@gmail.com

Este é um trabalho de acesso aberto e distribuído sob os Termos da CreativeCommonsAttributionLicense. A licença permite o uso, a distribuição e a reprodução irrestrita, em qualquer meio, desde que creditado as fontes originais.

Imagem: StockPhotos (Todos os direitos reservados).

\section{Open Access}

Resumo: Em tempos de grande sofrimento pela perda em massa de seres humanos por uma doença desconhecida, devastadora e que não tem predefinição a quem contaminar, vivencia-se também outra aflição tão grande quanto a perda propriamente dita: essa consternação refere-se ao luto solitário, na qual os enlutados ficam distante do que muitas vezes seria o alento esperado, como o acolhimento e o último adeus. Supondo-se que o acolhimento humano e espiritual se faz necessário no momento vivenciado de pandemia, o objetivo deste estudo é destacar a importância do acolhimento espiritual e/ou religioso para amparo de familiares que perderam um ente querido em decorrência do Covid-19. A metodologia utilizada é a revisão de literatura. Evidenciou-se que a pandemia é um acontecimento devastador, causando grande sofrimento psíquico, tanto para familiares e pacientes acometidos, quanto para a sociedade em geral. Conclui-se que o amparo espiritual se faz necessário tanto para o paciente quanto para o familiar enlutado, haja vista o momento pandêmico, rodeado de grande incerteza e sofrimento coletivo.

Palavras-chave: Saúde mental. Espiritualidade. Enfermagem. Luto. Covid19.

Abstract: In times of great suffering due to the mass loss of human beings to an unknown, devastating disease that has no predefined whom to infect, another affliction as great as the loss itself is also experienced: this consternation refers to solitary mourning, in which the mourners are far from what would often be the expected encouragement, such as the welcome and the last goodbye. Assuming that human and spiritual care is necessary at the time a pandemic is experienced, the aim of this study is to highlight the importance of spiritual and/or religious care to support family members who have lost a loved one as a result of Covid-19. The methodology used is the literature review. It was evident that the pandemic is a devastating event, causing great psychological distress, both for affected family members and patients, as well as for society in general. It is concluded that spiritual support is necessary for both the patient and the bereaved family member, given the pandemic moment, surrounded by great uncertainty and collective suffering.

Keywords: Mental health. Spirituality. Nursing. Grief. Covid-19. 


\section{Introdução}

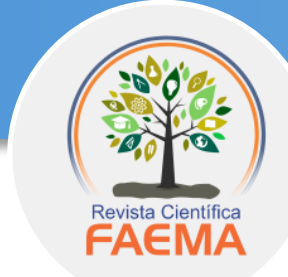

A espiritualidade é entendida como parte de grande importância na vida do ser humano. Devido à atual crise sanitária pelo Covid-19, apresenta-se uma difícil organização de aspectos em relação à estrutura do sistema de saúde, aos suprimentos e insumos básicos da vida, a economia, a fome, as adversidades, o desamparo igualitário, a discriminação pelos moradores de rua e refugiados, entre diversos outros casos de vulnerabilidade social. As incertezas, aflições e temores sobre a pandemia, reaparecem com mais intensidade através da possibilidade de contaminação, agravamento, sequelas e morte gerada pelo novo coronavírus ${ }^{(1)}$.

A religião, de forma geral, é uma expressão da civilidade humana, por isso é capaz de cultivar a motivação de seus seguidores leais e admiradores. Em tempos em que não há pandemia, a religião já executava o papel social de guiar a área espiritual e o comportamento das pessoas. Nesse momento vivenciado, essas ações são amplificadas para a sociedade em geral, a fim de auxiliar o coletivo no processo de tomada de decisões e enfrentamento das provações ${ }^{(2)}$.

Lideranças, ONGs e grupos religiosos realizam várias ações de grande importância para ajudar pessoas e diminuir o choque da Covid-19. Eles fornecem apoio, consolo, conselhos, direções a adotar, precauções referentes ao bemestar, como também serviços sociais para toda sociedade. Essas entidades religiosas transferem esses conhecimentos de cuidados a fim de proteger seus membros e os demais. Na maioria das vezes, essas ações são bem recebidas e seguidas (3).

Devido ao aumento dos casos de infecção e alta transmissibilidades do vírus, as autoridades políticas e sanitárias têm elaborado decretos de medidas restritivas mais rigorosas, na tentativa de impedir o crescimento da doença, sendo assim, estão mantendo fechadas as faculdades e escolas, templos religiosos, restringindo excursões, cerimônias culturais e festas, entre outras medidas de cuidados públicos e pessoais ${ }^{(4)}$. 


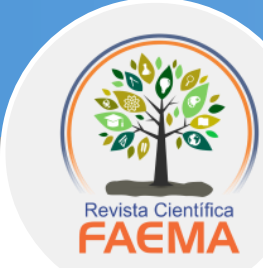

Desse modo, as reuniões religiosas presenciais não podem ser desempenhadas como de costume, por conta das normas das autoridades de saúde estaduais e municipais, sendo assim, suas programações são de modo remoto, ou seja, via de transmissão online, embora devesse ser reconhecida como um dos serviços essenciais, pois esses encontros podem ajudar a conservar a saúde mental e prevenir o agravamento do luto, visto que elas entusiasmam psicodinamicamente, contribuindo com a pessoa nas diferentes precisões de sua existência ${ }^{(3)}$. Observando essa premissa de acolhimento, o objetivo da pesquisa é destacar a importância do acolhimento espiritual e ou religioso para amparo de familiares que perderam um ente querido para Covid-19.

\section{Metodologia}

A presente pesquisa usou como metodologia a revisão de literatura, de carácter descritivo e exploratório, com materiais indexados e disponibilizados nas seguintes bases de dados: Biblioteca Virtual da Saúde (BVS), Scientific Eletronic Library Online (SciELO), Literatura Latino-Americana e do Caribe em Ciências da Saúde (LILACS), Acervo da Organização Pan-Americana de Saúde (OPAS), Sistema de Informação da Organização Mundial de Saúde (OMS), o acervo da Biblioteca Júlio Bordignon, além do arquivo pessoal das autoras. Como delimitação temporal priorizou-se o último quinquênio, que compreendem os anos de 2016 ao ano de 2021.

No entanto, foram utilizados materiais fora deste período, a justificava é o material ser de alta relevância, a citar: Ligações NANDA - NOC - NIC: condições clínicas: suporte ao raciocínio e assistência de qualidade, 2012; A ciência do bom viver: princípios para restaurar a saúde e manter o bem-estar, 2007. Todo material pesquisado foi selecionado, analisado e utilizado de acordo com os critérios de 


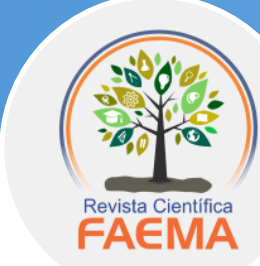

inclusão, que foram categorizados em: materiais escritos na íntegra, não duplicados, com relevância à temática da pesquisa, base de dados confiáveis, disponíveis em idioma português, inglês e espanhol. Já como critérios de exclusão: materiais desconexos com o tema, inconclusos, duplicados e os que não estivessem nos idiomas português, inglês e espanhol. Para a pesquisa utilizaram-se os seguintes Descritores em Ciências da Saúde (DeCS): Saúde mental, Espiritualidade, Enfermagem e Covid19. Ao decorrer da busca por materiais, foram pesquisadas e encontradas 30 obras. Deste total, foram utilizadas 24 referências, sendo 11 artigos científicos; 02 trabalhos de conclusão de curso; 06 periódicos divulgados em revistas eletrônicas e 05 livros.

\section{Resultados e Discussão}

\section{Pandemia pelo Corona vírus}

A patologia ocasionada pelo CoronavirusDisease 2019 (Covid-19), foi primeiramente relatada na China, em dezembro de 2019 (4). As primeiras ocorrências de Covid-19 apresentaram-se a cidade chinesa de Wuhan, onde havia uma exposição habitual de um comércio para atacados de frutos do mar, o qual, por sua vez, também negociava animais vivos. Em 31 de dezembro do referido ano, a China declarou o surto à Organização Mundial da Saúde (OMS), e no dia posterior, encerrou as atividades do mercado onde se relataram os casos iniciais. Desde então, houve crescimento considerável de números casos e a certificação da propagação em massa ${ }^{(5)}$. 


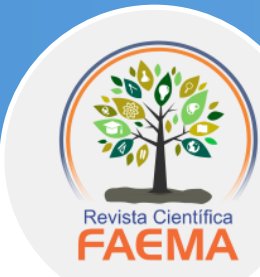

Diante o exposto, e da confirmação dos números de casos e mortes aumentando, a Organização Mundial da Saúde (OMS), em 11 de março de 2020, divulgou que o surto da doença Covid-19, ocasionada pelo coronavírus (SARS-CoV-2), qualificava-se como uma pandemia ${ }^{(6)}$.

As pesquisas apontam sobre os sintomas da Covid-19 que são: cansaço, tosse, febre, dificuldade respiratória, perda do paladar e olfato. Embora a maior parte dos infectados (aproximadamente 80\%) revelem sintomas sutis ou moderados, uma considerável quantidade de casos necessita de admissão hospitalar ou, até mesmo, de recurso terapêutico em (UTI) ${ }^{(4)}$.

Crepald et al. (2020) afirmam que a Covid-19 tem sido classificada como uma severa crise, tanto do ponto de vista epidemiológico quanto psicológico. Além disso, as perdas consecutivas em curto espaço de tempo esbarram nos contratempos para realizar cerimônias de partida ou o último adeus entre os indivíduos a beira da morte e seus familiares, assim como os cerimoniais fúnebres, podendo intensificar ainda mais a vivência de luto ${ }^{(4)}$.

\section{A busca por apoio espiritual como forma de acolhimento}

Antigamente, buscava-se na religião as curas para todos os males por meio do contato físico, realizando rituais, entre outras maneiras utilizadas por cada uma dentro de seus princípios, dessa forma, os relatos de curas e milagres permeiam a sociedade há milhares de anos. Atualmente, multiplicaram-se essas buscas presenciais, para o fortalecimento emocional e espiritual com a intenção de obter ajuda para lidar e superar as aflições vivenciadas nesse momento de pandemia pelo Covid-19, pois os fiéis se sentem acolhidos, protegidos e muitos conseguem alcançar segurança e obter esperança para dias melhores ${ }^{(7)}$. 


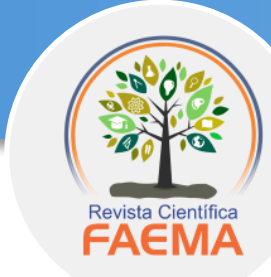

Nas escrituras sagradas, o que para a fé cristã trata-se da Bíblia, é mencionado um exemplo de indicação para buscar a cura das enfermidades do indivíduo através da igreja, no livro de Tiago capítulo 5, versículos 14 e 15, que relatam:

\footnotetext{
Entre vocês há alguém que está enfermo, mande chamar os presbíteros da igreja, para que orem sobre ele e unjam com azeite, em nome do Senhor. As orações realizadas com fé curarão os doentes; o Senhor os erguerás (BÍBLIA SAGRADA, LIVRO DE TIAGO 5:14-15).
}

Os fiéis conhecedores e seguidores dessas escrituras buscam esses meios a fim de receber a cura divina até os dias de atuais. Outro verso da Bíblia que se torna um incentivo para a busca das reuniões religiosas é apresentado em Êxodo capítulo 23 e versículo 25, dizendo assim: “Ofereçam culto ao Senhor, o Deus de vocês, e Ele derramará bênção, dando a todos o alimento e a água e tirarei a doença do meio de vocês." Muitas pessoas pensam que só serão ouvidas e atendidas se estiverem realizando suas adorações em seus templos religiosos, com a união de todos os demais membros, e a falta no momento dessas celebrações deixa esses fiéis seguidores abalados e com sentimento de abandono pelo universo divino ${ }^{(9)}$.

Nesse momento de pandemia, o mundo está passando por uma fase de luto coletivo, em função das perdas em massa. Em tempos de normalidade, é de costume a realização de velórios em templos religiosos para a última despedida e entrega daquele corpo e alma de acordo com cada cultura. Esse ritual é considerado de suma importância, pois as pessoas podem ter o apoio e conforto uma das outras, conseguindo amparo afetivo e espiritual, recebendo apoio no enfrentamento de suas emoções. Na ausência dos cerimoniais fúnebres por conta do grande risco de infecção com o Covid-19, torna-se mais difícil conhecer e lidar psicologicamente com a perda (6). 


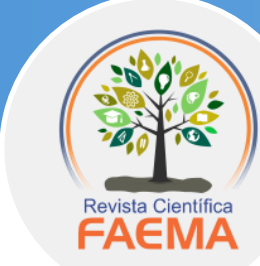

A chegada do Covid-19 é apontada com adversidade, capaz de afetar o sistema internacional e afligir a estrutura da religião global organizada, isso evidencia a capacidade da doença em afligir de diversas formas a sociedade em geral, incluindo sua religiosidade. Para tanto, é necessário compreender as mensagens transmitidas pelos líderes globais e religiosos, para que haja continuidade dessas instituições ${ }^{(10)}$.

Carlet (2021), menciona sobre o discurso público referente ao Coronavírus, que igualmente pode se modificar dependendo da religiosidade de cada indivíduo. No Irã, Brasil, Índia e Turquia, a ligação entre religiosidade e ciência é naturalmente abordada em público.

O Covid-19 está provando a religião organizada e, como consequência, as pessoas são capazes de inicialmente enxergar rituais religiosos cheios com suspeita quando a pandemia se findar, levando pessoas religiosas a exercer sua fé de forma mais individual. Independentemente da religião, o fim das atividades nos locais mais sagrados como por exemplo, do Islã, em Meca, na Arábia Saudita, e o isolamento do Papa Francisco envolverá maior ocupação na memória da juventude (11).

Uma congregação cristã na Coréia do Sul deu origem a uma enorme porcentagem de casos de Covid-19. Após inicialmente ocorrer êxito em diminuir o alastramento, deu-se um crescimento súbito de casos, iniciando-se na terceira semana de fevereiro de 2020, vindo de um paciente infectado que costumava ir à Igreja de Jesus Shincheonji. Nesse culto, acredita-se que a doença é um pecado, e o enfermo deve seguir às orações para expiar o pecado ${ }^{(12)}$.

A Igreja do Santo Sepulcro, onde se presume ter ocorrido crucificação e sepultamento de Jesus Cristo, foi fechada. A última vez que suas grandes portas foram fechadas foi em meio a Páscoa em 1349, quando a Peste Negra avassalou a Europa ${ }^{(13)}$. 


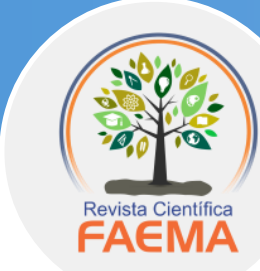

Por outro lado, quando se refere ao acolhimento religioso espiritual, este ato tem como características de ser mais aberto para todas as pessoas da sociedade, independentemente de suas crenças e culturas. Na atualidade, a área da saúde demonstra um aumento de reconhecimento sobre religiosidade e espiritualismo, sendo empregados como maneiras de amparos ao sofrimento emocional ocasionado pelo momento de enfermidade. Desse modo, a religião e o espiritualismo são considerados elementos de grande importância para a vida do ser humano, pois esses mesmos elementos estimulam a comunicação social e cultural, além de afetar positivamente o aspecto psicológico ${ }^{(14)}$.

Devido à pandemia do Covid-19, todos os encontros e programações espirituais tiveram de empregar novas medidas para serem realizadas, sendo assim, foram se adaptando para os meios virtuais de transmissão das celebrações, cerimônias e rituais ou outros meios, como televisão e rádio. As lideranças eclesiásticas se adaptaram para dar suporte e apoio a seus fiéis e seguidores, em particular pelas redes sociais e ou por ligações. Mesmo com a flexibilidade dos decretos governamentais, é importante seguir as medidas estabelecidas pelos governos para evitar a propagação do vírus ${ }^{(15)}$.

\section{A enfermagem e os cuidados espirituais}

Ao olhar para as antigas histórias referente à criação da enfermagem, é possível observar que essa carreira profissional surgiu aproximada da religião. As Religiosas de Caridade da Casa de São Vicente de Paula, no ano de 1617, iniciaram a convocação de diversas mulheres católicas, com o objetivo de prestar assistência para os hospitais religiosos, como também para outros laicos. 


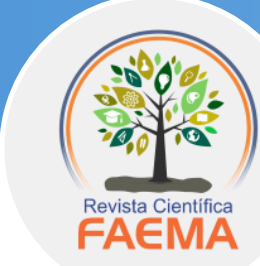

No ano de 1789, havia cerca de 400 casas de saúde administradas por essas mulheres no país francês. Florence Nightingale, reformadora social inglesa, estaticista e fundadora da enfermagem moderna, procurou aprender e treinar com essas religiosas da caridade e diaconisas protestantes e assim foram empregando os conceitos adquiridos (16).

É de suma importância os profissionais de enfermagem obterem conhecimento sobre o real significado da religião de seus pacientes, para assim prestar uma assistência adequada sobre a situação. A realização da anamnese espiritual em cada enfermo possibilita o entendimento mais profundo da importância da crença para seus pacientes, isso permite a identificação das prioridades e do que ele necessita para ser atendido ${ }^{(17)}$.

Foi estabelecida por Florence Nightingale uma base simples, porém fundamental, dos cuidados da enfermagem que precisam estar vinculados aos princípios da religiosidade e era de suma importância para os enfermeiros terem esses conhecimentos dos ensinamentos de diversas entidades religiosas, como por exemplo, a capacidade do cuidado com a saúde mental, baseado nos princípios da religião, apontados como essenciais para a prevenção de problemas mentais ${ }^{(16)}$.

A atenção para a espiritualidade não é apenas um grupo de interferências, abrange até mesmo as ações de cuidados. Compete aos programas realizados por profissionais de saúde, com atividades focadas para promover conforto, contentamento, entusiasmo, esperança e vontade de viver (17).

A espiritualidade tem como a finalidade aprimorar o bem-estar, conduzir energia e dar sentido as fases da vida, vista como um conjunto de crenças que seguem componentes intocáveis, capaz de suportar sentimentos esgotantes, podendo ou não interligar uma ação religiosa, então a conexão entre saúde e espiritualidade é real, na qual o ser humano é formado pela característica espiritual, sendo a espiritualidade um ponto que interliga aspectos biológicos, psicológicos e sociais do ser humano (17). 


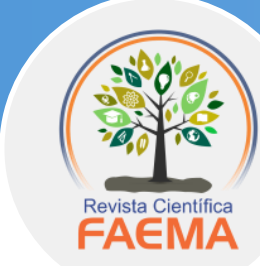

Para tanto, a espiritualidade vem com uma perspectiva que serve de amparo para os pacientes e para a equipe de enfermagem, em sua relevância diante da morte, a fim de encontrar sentido para temas existenciais, dá a equipe de enfermagem também precisa valorizar a espiritualidade que faz parte do ser humano, independentemente de crenças ${ }^{(18)}$.

Segundo Santos (2020), quando a espiritualidade é exercida dentro das unidades hospitalares, não obrigatoriamente está interligada a uma religião, mas como a essência do próprio conceito de espiritualidade, tal qual aborda importância de valores humanos como: a empatia, a compaixão, amor e o cuidado ofertado (19).

Quando se tem uma crença em um ser superior, facilita, expressivamente, os profissionais de saúde a conduzir seus níveis de estresse, agindo como ponto de equilíbrio diante de circunstâncias esgotantes que o trabalho acarreta. Sendo assim, a espiritualidade funciona como amparo e interfere diretamente no cuidado ofertado ao enfermo, interligado com a empatia do cuidado prestado ${ }^{(19)}$.

Estudos revelam que revelam que, na maioria dos casos de enfermos em fase final, há uma necessidade de conversar com o ministro do evangelho e/ou outro que possui o título no âmbito religioso, podendo acontecer em qualquer momento de sua fase enferma. O anseio de dialogar com uma autoridade religiosa, de poder acompanhar as celebrações pela televisão e a aceitação da espiritualidade, é de importante para o paciente e deve ser observado pela enfermeira (o), no entanto, primeiramente é preciso distinguir a orientação religiosa do paciente. Os enfermeiros consideram que a ajuda religiosa é eficaz para os doentes, pois, na medida com que a carência da religiosidade é suprida, esses pacientes encontram conforto, sentemse perdoados e alcançam o sentimento de paz com eles mesmos ${ }^{(18)}$. 


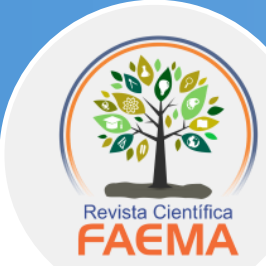

O atendimento holístico é um legado de grande relevância para a enfermagem, esses profissionais colocam em prática a empatia, atendem as precisões corporais, mentais e espirituais do paciente, são atitudes de grande importância para a assistência de qualidade, pois estão ligados nas particularidades de cada indivíduo ${ }^{(16)}$.

\section{Menezes (2017) relata que existem algumas opções a serem empregadas pelos} profissionais da enfermagem para atender o lado espiritual nas diferentes situações que atingem o paciente, tanto na assistência básica como domiciliar e hospitalar. Para exemplificar de forma clara, é exposto no quadro abaixo algumas das inúmeras opções de amparo ${ }^{(17)}$.

Quadro 1 - Ações de Enfermagem para conforto espiritual do paciente

\begin{tabular}{|c|c|}
\hline $\begin{array}{c}\text { Leituras de escrituras } \\
\text { religiosas }\end{array}$ & $\begin{array}{l}\text { Pacientes que estudam a religião comumente tem consigo mesmo livros e/ou escrituras } \\
\text { de sua religião. } 0 \text { enfermeiro (a) também pode ter em sua unidade de trabalho, livros e } \\
\text { ou revistas de mensagens que possam ser empregadas nessa ocasião; }\end{array}$ \\
\hline Oração & $\begin{array}{l}\text { Pode ser realizada por meio de palavras que procedem da emoção, daquela ocasião que } \\
\text { fica próximo a ele. Além disso, pode-se realizar orações populares, como exemplo a Ave } \\
\text { Maria, o Pai Nosso, podendo ser realizada pelo próprio enfermeiro (a), ou convidar o } \\
\text { paciente a realizar e/ou participar; }\end{array}$ \\
\hline Meditação & $\begin{array}{l}\text { Solicitar ao enfermo a fechar seus olhos e imaginar sobre algum cenário natural } \\
\text { externo, conduzindo ao silêncio interior, afastando-o provisoriamente de suas } \\
\text { ansiedades e angústias; }\end{array}$ \\
\hline Uso da música & $\begin{array}{l}\text { Sugerir ao paciente que cante uma canção de sua preferência, podendo ser religiosa ou } \\
\text { qualquer outra, pode-se também convidar algum componente da equipe } \\
\text { para cantar. Outra tática além dessa é através do telefone móvel conectar } \\
\text { alguma canção que o ajude a relaxar e traga recordações de suas convicções religiosas } \\
\text { e memórias dos bons períodos partilhados em sociedade; }\end{array}$ \\
\hline $\begin{array}{l}\text { Incentivo à } \\
\text { solidariedade }\end{array}$ & $\begin{array}{l}\text { As atividades humanitárias proporcionam o conforto, comodidade, aconchego, } \\
\text { contentamento, felicidade, satisfação, saúde, segurança, tranquilidade e traz a pessoa } \\
\text { para mais perto de suas divindades. Estas ações devem ser realizadas tanto em hospitais } \\
\text { como também nas comunidades; }\end{array}$ \\
\hline $\begin{array}{l}\text { Promover encontros } \\
\text { com os membros da } \\
\text { religião }\end{array}$ & $\begin{array}{l}\text { Proporcionar reuniões entre os integrantes religiosos, os pacientes que compreendem e } \\
\text { aceitam os mesmos conceitos sobre suas crenças, podem se unir para acompanhar as } \\
\text { apresentações religiosas pela TV ou pela rádio; }\end{array}$ \\
\hline Escutar o paciente & $\begin{array}{l}\text { Determinados casos as pessoas enfermas necessitam somente do profissional de } \\
\text { enfermagem para desabafar sobre as aflições do momento, e o enfermeiro(a) tem de } \\
\text { preparar um determinado momento bem satisfatório afim de prestar essa assistência de } \\
\text { escutar. Em algumas situações o } \quad \text { (a) precisa apenas que ouçam suas aflições, o } \\
\text { profissional de saúde deve dispor de tempo suficiente para a escuta qualificada. }\end{array}$ \\
\hline
\end{tabular}

Fonte: Menezes (2017); compilado pelas autoras (2021). 


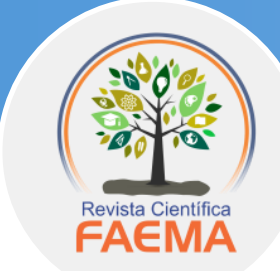

Segundo Whitte (2007), os pacientes necessitam ouvir palavras acolhedoras que os confortem. Os profissionais de enfermagem podem, de certa maneira, ler a Bíblia diariamente, para que possam se tornar mais habilitados a pronunciar essas palavras que auxiliem a pessoa enferma. Os indivíduos religiosos acreditam que existem anjos nos leitos desses pacientes e o ambiente que os cercam, e a alma de quem ali presta assistência terapêutica será digna e perfumada (20).

A crença religiosa e o espiritualismo foram considerados fontes de defrontação perante situações conturbadas e envolve-se de maneira assertiva na vida das pessoas, nos princípios de saúde mental e preceitos hematológicos, sugerindo que os enfermeiros que exercem suas crenças religiosas e espirituais demonstram ter uma saúde mental mais saudável, até mesmo com seu sistema imunológico fortificado e maior entendimento sobre bem-estar (21).

A religiosidade na assistência da saúde destaca que o profissional de enfermagem em seus atendimentos precisa obter conhecimento de si próprio, assim irá adquirir consciência de sua profundidade espiritual a ponto de ter a capacidade de lidar com firmeza nos elementos espirituais nos momentos de cuidados a serem prestados. Contudo, para o enfermeiro conhecer, diferenciar e executar a área espiritual nos usuários, se torna necessário primeiramente ser mais concentrado e cauteloso nesses assuntos para si mesmo ${ }^{(22)}$.

A área espiritual e religiosa demonstra grande importância na vida das pessoas em geral, pois é reconhecida oficialmente como um dos diagnósticos a serem executados pela equipe de enfermagem. No livro de NANDA 2018-2020 no domínio 10 princípios da vida e no livro de ligações NANDA-NOC-NIC-2012, aponta vários diagnósticos e suas intervenções ${ }^{(23,24)}$. Seguem alguns deles no quadro 2 : 


\section{Quadro 2 - Diagnósticos de enfermagem e suas Intervenções.}

\begin{tabular}{|c|l|}
\hline $\begin{array}{c}\text { DIAGNÓSTICO DE } \\
\text { ENFERMAGEM }\end{array}$ & \multicolumn{1}{c|}{ INTERVENÇÃo DE ENFERMAGEM } \\
\hline $\begin{array}{c}\text { Disposição para } \\
\text { bem-estar espiritual } \\
\text { melhorado }\end{array}$ & $\begin{array}{l}\text { Evolução no ânimo; suporte eclesiástico; orientação dos princípios; auxílio para o } \\
\text { fortalecimento mental; biblioterapia; simplificar as atividades de reflexão; } \\
\text { musicoterapia; promover a disposição da resistência e superação; medidas preventivas } \\
\text { para submissão eclesiástica. }\end{array}$ \\
\hline $\begin{array}{c}\text { Religiosidade } \\
\text { prejudicada }\end{array}$ & $\begin{array}{l}\text { Assistência para reduzir aflição; Conforto para as emoções; fornecer suporte devocional; } \\
\text { simplificar o sentimento de culpabilidade; auxiliar na autopercepção; apoiar nas decisões } \\
\text { tomadas; ouvir atentamente; facilitar os meios para meditar; estimular a participar de } \\
\text { rituais de acordo com suas crenças. }\end{array}$ \\
\hline $\begin{array}{c}\text { Risco de } \\
\text { preligiosidade }\end{array}$ & $\begin{array}{l}\text { Assistência para reduzir a inquietação e tomar decisões; intermediação cultural; } \\
\text { mobilizar os familiares; fornecer alívio a dor; reduzir a exaustão e depressão; identificar } \\
\text { os riscos; garantir proteção e cuidados; facilitar o fortalecimento eclesiástico; melhorar } \\
\text { o grupo de acolhimento e supervisionar. }\end{array}$ \\
\hline $\begin{array}{c}\text { Sofrimento espiritual } \\
\text { Assistência para tomar decisões; controle para a angústia; auxílio no momento de morte; } \\
\text { amparo para as emoções; promover a inclusão dos familiares; simplificação do } \\
\text { procedimento de dor e culpabilidade e pesar; facilitar e apoiar o fortalecimento } \\
\text { espiritual; promover o equilíbrio do temperamento; estimular a participar de cerimoniais } \\
\text { religiosos; promover esperança; terapia de recordações; facilitar os meios para } \\
\text { meditação. }\end{array}$ \\
\hline $\begin{array}{c}\text { Identificar e controlar o risco; conter a aflição; intervir em desavenças; melhora do } \\
\text { Risco de sofrimento } \\
\text { espiritual }\end{array}$ & $\begin{array}{l}\text { enfrentamento; assistência ao morrer; manter em domínio o ambiente oferecendo } \\
\text { aconchego, segurança e alívio da dor; simplificar os processos de perdão e de pesar; } \\
\text { promover esperança; equilíbrio do temperamento; controle da dor; estimular a participar } \\
\text { de cerimoniais religiosos; reduzir o estresse por mudança; terapia de Reminiscências; } \\
\text { melhorar a autoestima, assistência espiritual; promover possibilidades e confiança; }\end{array}$ \\
\hline
\end{tabular}

Fonte: Nanda (2018); Johnson, et al. (2012).

Nota-se que todos esses diagnósticos de enfermagem e suas intervenções são de grande relevância, porém pouco utilizados pelos enfermeiros. Os enfermeiros que prestam assistências aos pacientes devem obter compreensão sobre a seriedade no cuidado das leis da saúde. Em nenhuma outra área tem mais importância para seguir de forma correta esses princípios como no quarto do paciente, a não utilização desse modo de assistência poderá ocorrer implicações. Em situações de enfermidades graves, o mínimo de negligência, a ausência de atenção para as necessidades específicas desse paciente, a demonstração de receio, inquietação ou falta de paciência e da empatia poderá colocá-lo em uma situação ainda mais delicada ${ }^{(20)}$. 


\section{Conclusão}

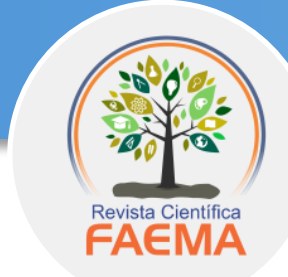

0 presente artigo trouxe a importância do acolhimento espiritual às pessoas nesse momento atual de pandemia pelo Covid-19, deixando explícito que o paciente necessita desse acolhimento em seu leito, tanto quanto o familiar que vivencia o luto. 0 momento pandêmico tem ocasionado grandes prejuízos na saúde mental e física, não só para os que já sofreram e sofrem essa infecção e ainda estão em tratamento, mas também tem afetado aos demais, como os profissionais da saúde e toda a comunidade que ainda não foi acometida.

Sabe-se que pandemias provocam óbitos em grande escala em um pequeno intervalo de tempo, acarretando inúmeros problemas psicológicos. Se tratando de Covid-19, diversas precauções foram adotadas para diminuir a contaminação em grande número, dentre elas restrições às viagens e distanciamento social, diminuindo então a interação do adoecido com seu convívio familiar e cultos religiosos.

A pandemia pelo Covid-19 tem afetado a vivência de terminalidade, morte e luto. Sendo assim, intervenções são necessárias neste contexto. A espiritualidade e a religião se tornam uma ferramenta relevante para muitas famílias, auxiliando na luta contra as barreiras da vida, na moldagem do enfrentamento do luto. A espiritualidade e a religião ajudam na forma de enfrentar momentos difíceis, trazendo consolo no momento de terminalidade como o luto.

A enfermagem traz consigo essa importante missão de saber reconhecer que o seu papel faz toda a diferença na vivência da terminalidade do paciente, vai muito além de sinais e sintomas, mas da percepção do profissional de saber acolher de forma humanizada. Nessa situação de pandemia, o profissional enfermeiro é o que tem maior contato face a face com o paciente, tornando-se intermediador entre paciente e sua família, assim se evidencia a importância dessa profissão como um todo. 


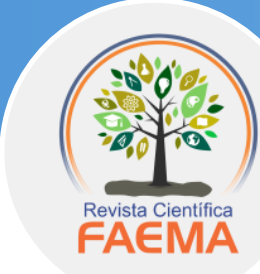

Portanto, o acolhimento espiritual é de grande relevância, tanto para o paciente acometido pela Covid-19 em seu leito hospitalar, quanto para os familiares que enlutados ficaram e perpassam por momentos de grande sofrimento, tanto pela perda do ente querido quanto pela ausência de rituais em grupo. O estudo deixa margem para que novas pesquisas sejam realizadas, agregando assim maior relevância ao tema.

\section{Referências}

1- Tavares CQ. Dimensões do cuidado na perspectiva da espiritualidade durante a pandemia pelo novo coronavírus (COVID-19). J Health NPEPS. 2020; 5(1):1-4. Disponível em: https://periodicos.unemat.br/index.php/jhnpeps/article/view/4517.

2- Nascimento AL, Tozi DR. A gestão social das religiões no mundo da pandemia: notícias das religiões de matriz africana e os seus discursos em torno da cura da terra. RIGS revista interdisciplinar de gestão social v.10 n.1 jan./abr. 2021. Disponível em: PDF.

3- OMS- Organização Mundial da Saúde. Considerações e recomendações práticas para líderes religiosos e comunidades de fé no contexto da COVID-19. Orientações provisórias. 7 de abril de 2020. Disponível em:https: / /www.ufrgs.br/coronavirus/wp-content/uploads/2020/05/COVID-19L\%C3\%ADderes-religiosos-e-comunidades-de-f\%C3\%A9.pdf.

4- Crepaldi MA, Schmidt B, Noal DS, Bolze DAS, Gabarra LM. Terminalidade, Morte e Luto na Pandemia de COVID-19: Demandas Psicológicas Emergentes e Implicações Práticas. Campinas, 2020. Disponível em: https: / / www.scielo.br/scielo.php?script=sci_arttext\&pid=S0103$166 \times 2020000100508$.

5- Aquino EML, Silveira IH, Pescarini JM, Aquino R, Filho JAS, Rocha AS, et al. Medidas de distanciamento social no controle da pandemia de COVID-19: potenciais impactos e desafios no Brasil. Ciência \& Saúde Coletiva, 25(Supl.1):2423-2446, 2020. Disponível em: https://www.scielosp.org/pdf/csc/2020.v25suppl1/2423$2446 /$. 
6- Cardoso EAO, Silva BCA, Santos JH, Lotério LS, Accoroni AG, Santos MA. O efeito da supressão de rituais fúnebres durante a pandemia de COVID-19 em famílias enlutadas. Rev. Latino-Am. Enfermagem vol.28 Ribeirão Preto 2020. Disponível: https:// www.scielo.br/scielo.php?script=sci_arttext\&pid=S010411692020000100405.

7- Nunes AP, Mariz C, Faerstein E. Saúde, Religião e Trânsito Religioso: Estudo PróSaúde. Rio de Janeiro, 2016. Disponível em:

https: / /www.scielo.br/scielo.php?script=sci_arttext\&pid=S001152582016000401241.

8- Bíblia de Estudo Plenitude para Jovens: Crescendo no poder da Palavra de Deus.Antigo e Novo Testamento. Tradução de Helena, MS, et al. Barueri-SP: Sociedade Bíblica do Brasil, 2008. P. 1610-1611.

9- Bíblia, português. A Bíblia Sagrada: Antigo e Novo Testamento. Tradução de João Ferreira de Almeida. Edição revisada e atualizada no Brasil. $2^{a}$ ed. São Paulo: Sociedade Bíblia do Brasil, 1993. P. 82.

10- Carletti A, Nobre F. A religião global no contexto da pandemia de Covid-19 e as implicações político-religiosas no Brasil. Revista Brasileira de História das Religiões. ANPUH, Ano XIII, n.39, janeiro/abril de 2021 - ISSN 1983-2850 Disponível em: https://periodicos.uem.br/ojs/index.php/RbhrAnpuh/article/view/56601.

11- Kilgore E. COVID-19 é uma religião organizada para o teste do demônio. Disponível em: https://nymag.com/intelligencer/2020/03/the-coronavirus-istesting-organized-religion.html.

12- Park N. Cults and conservatives spread coronavirus in South Korea. Foreign Policy, 2020. Disponível em: https: //foreignpolicy.com/2020/02/27/coronavirussouth-korea-cults-conservatives-china/.

13- Scammell R. An 'extraordinary' Easter in Jerusalem amid coronavirus closures. Aljazeera. Disponível em: https://www.aljazeera.com/news/2020/4/10/anextraordinary-easter-in-jerusalem-amid-coronavirusclosures?utm_source=website\&utm_medium=article_page\&utm_camp.

14- Zerbetto SR, Gonçalves AMS, Santile N, Galera SAF, Acorinte AC, Giovannetti G. Religiosidade e espiritualidade: mecanismos de influência positiva sobre a vida e tratamento do alcoolista. Esc. Anna Nery vol.21 n.1. Rio de Janeiro 2017. Disponível em: https://www.scielo.br/scielo.php?script=sci_arttext\&pid=S141481452017000100205. 


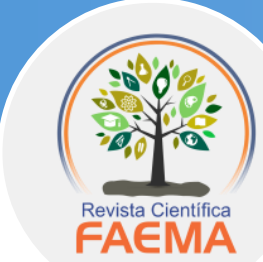

15- Oliveira, MD. Cuidado pastoral da Igreja em tempos de pandemia: Covid-19. Revista Caminhando v. 25, n. 1, p. 257-276, jan./abr. 2020. Disponível em:https://www.metodista.br/revistas/revistasmetodista/index.php/Caminhando/ article/view/10336/7240.

16- Abdala GA, Meira MDD, Oliveira SLSS, Santos DC. Religião, espiritualidade e a enfermagem. REFACS, Uberaba, MG, v. 5, p. 154-164, 2017. Supl. 1. Disponível em: http://dx.doi.org/10.18554/refacs.v5i0.2001.

17- Menezes TMO. Dimensão espiritual do cuidado na saúde e enfermagem. Rev. baiana enferm. (2017). Disponível em: PDF.

18- Souza JLG, Ferreira LP, Loiola MP, Silva TB. Enfermagem no enfrentamento de situações de morte ou quase morte pediátrica: Avaliação do bem-estar espiritual. Ariquemes-RO, Faculdade de Educação e Meio Ambiente Faema 2018. Disponível em: pdf.

19- Santos BA. Consequências da sobrecarga de trabalho para a saúde mental dos profissionais de enfermagem. Ariquemes-RO, Faculdade de Educação e Meio Ambiente Faema 2020. Disponível em: pdf.

20- Whitte EG. A ciência do bom viver: princípios para restaurar a saúde e manter o bem-estar. Tradução de Carlos A. Trezza. 1a . Edição. Tatuí-SP: Casa Publicadora Brasileira, 2007. P. 84-86.

21- Carneiro EM, Arantes JP, Silva DAA, Catarino JS, Junior VR, Borges MF. religiosidade/espiritualidade, indicadores de saúde mental e parâmetros hematológicos de profissionais de enfermagem. Uberaba-MG, Jul 2020. Disponível em: https://pesquisa.bvsalud.org/portal/resource/pt/biblio-1117959.

22- Lene A, Fernandes RAQ, Puggina AC. A espiritualidade de enfermeiros assistenciais interfere no registro do diagnóstico sofrimento espiritual?. São Pualo, 2017. Disponível em: https://www.scielo.br/pdf/ean/v22n1/pt_1414-8145-ean2177-9465-EAN-2017-0082.pdf.

23- Nanda-I. Diagnósticos de Enfermagem da NANDA: Definições e classificação 2018-2020/ [NANDA Internacional]. Tradução Regina Machado Garcez; revisão técnica: 16-Alba Lucia Bottura Leite de Barros, et al. 11. Ed. Porto Alegre: Artmed, 2018. P. 355-363.

24- Ligações NANDA - NOC - NIC: condições clínicas: suporte ao raciocínio e assistência de qualidade. Mario Johnson. et al.; tradução de Soraya Imon de Oliveira. $3^{a}$ edição. Rio de Janeiro: Elsevier, 2012. P. 138-140 e 275. 